\title{
Effect of Yoga Breathing Exercises on Ventilatory Function
}

\author{
Banstola $\mathrm{D}^{* *}$ \\ 'Associate professor, Physiology Department \\ Institute of Medicine, Maharajgunj, Kathmandu, Nepal
}

\section{Keywords \\ Yoga, Breathing exercise, \\ Ventilatory function. \\ Corresponding author \\ Dinesh Banstola, Associate professor \\ Physiology Department \\ Institute of Medicine, Maharajgunj, \\ Kathmandu, Nepal \\ Email: dinesh_banstola@hotmail.com}

\begin{abstract}
Introduction: Controlled breathing not only keeps your mind and body functioning at their best, it can also lower blood pressure, promote feelings of calm and relaxation and help you de-stress. Many experts encourage using the yoga breathing exercises as a means of increasing awareness, mindfulness and reducing anxiety. Over-worked, under-slept, and feeling pressure may impair breathing pattern. There are some yoga breathing exercise techniques that improve ventilatory function.
\end{abstract}

Objective: To assess the effect of yoga breathing exercises on their ventilatory function.

Methods: Forty eight male and female students of 18 - 30 years were involved in the study of ventilatory function before and after yoga breathing exercise. Pulmonary function tests were performed with the subject sitting in a comfortable chair. Initial recording of tidal volume, inspiratory capacity, inspiratory reserve volume, expiratory reserve volume, forced vital capacity, and timed vital capacity in one second were measured.

Results: There was significant increase in inspiratory reserve volume, expiratory reserve volume, vital capacity, forced expiratory volume in one second and forced vital capacity after yoga breathing exercise.

Conclusion: Yoga breathing exercise improves ventilatory function.

\section{INTRODUCTION}

Controlled breathing not only keeps your mind and body functioning at their best, it can also lower blood pressure, promote feelings of calm and relaxation and help you destress. Many experts encourage using the yoga breathing exercises as a means of increasing awareness, mindfulness and reducing anxiety. Over-worked, under-slept, and feeling pressure may impair breathing pattern. There are some yoga breathing exercise techniques that improve ventilatory function ${ }^{1-4}$.

Breathing is synonymous with being alive. Correct breathing leads to proper ventilation and oxygenation ${ }^{5-9}$. Breathing even though finely controlled by neural and chemical feedback mechanisms can be affected by many ways e.g. stress, anxiety, panic states, abdominal and thoracic trauma and surgery apart from diseases of respiratory system ${ }^{10-15}$. Breathing exercise is used widely in clinical medicine as one of the methods of physiotherapy. It is also used in everyday life as a part of relaxation technique to alleviate stress and to regularize breathing pattern.

Certain guided breathing exercises are being used like yoga, pranayama and chants are advocated to improve pulmonary function. Respiratory muscles strengthening were tried using music therapy exercise. Effects of meditation and mental chanting of "OM" on certain 
physiolological parameters has been studied by several workers. These studies show increased alertness, autonomic changes, physical relaxation, changes in oxygen consumption, and basal metabolic rate. Large number of literature is available on the effects of music therapy. Listening to specific "ragas" is said to improve health, bring down elevated blood pressure, relieve headache and abdominal pain. No extensive study has gone into the mechanism of such therapy benefits.

Effect of yoga breathing exercises on their ventilatory function has not been so far studied. The present investigation was to assess the certain pulmonary functions before and after yoga breathing exercise in young male and female students.

\section{OBJECTIVE}

To assess the effect of yoga breathing exercises on their ventilatory function.

\section{METHODS}

Forty eight students were involved in the study of ventilatory function before and after yoga breathing exercise. Both male and female students were involved. The students were within 18 to 30 year age groups.

\section{Inclusion criteria}

1. Subjects 18 - 30 years without respiratory problems

2. Non-smokers

3. Subjects without history of chronic cardiovascular disease

4. Subjects without history of allergy that affects breathing

\section{Exclusion criteria}

1. Subjects with upper respiratory tract infections and any sort of other respiratory disorders

2. Subjects with smoking habits

3. Subjects with history of chronic cardiovascular disease

4. Subjects with history of allergy that affects breathing

All tests were done at the same time of the day to avoid possible diurnal variation. Informed consent was obtained from each volunteered student for this study.

Pulmonary function tests were performed in Knippingopen spirometer C.F. Palmer Ltd, London, England. Before each test the subject was familiarized with the instrument and a detailed instruction cum demonstration upto the satisfaction was given. All the procedures were carried out in the postgraduate laboratory, Physiology Department, IOM.

During the test, the subjects were adequately encouraged to perform at their optimum level. The forced respiratory maneuvers were repeated at least five times and the highest values were considered for the analysis.

Pulmonary function tests were performed with the subject sitting in a comfortable chair. After reassurance, the procedure was explained. Initial measurement of tidal volume (TV), inspiratory capacity (IC), inspiratory reserve volume (IRV), expiratory reserve volume (ERV), forced vital capacity (FVC) and timed vital capacity in one second (FEV1) measured. Breaths interrupted by swallowing or coughing were identified and discarded.

Spirometry is a procedure that measures the volume of air an individual inhales or exhales as a function of time $^{1-11}$. The measurement was performed with the subject in an upright position, usually seated. Procedure was demonstrated till subjects were clear regarding the technique. Subjects were given instruction to loosen their clothes that might restrict the movement of the chest and upper abdomen.

\section{Yoga breathing exercises session}

After initial recording of the above tests, the yoga breathing exercise was administered at morning time, in small groups of six to eight people. All subjects were put through daily practice of "yoga breathing exercise" for one hour each day for 60 days.

\section{Method 1: Bhastrika pranayam: Bellows breath}

1. Breathe in deeply through your nostrils. First, feel the diaphragm move down, allowing the lungs to expand and forcing the abdomen out; then feel your chest expand with your collar bones rising last.

2. Breath out quickly through your nostrils. Feel your collar bones dropping, chest deflating, and abdomen shrinking as the lungs collapse. This process of exhaling should be much faster than the process of inhaling - almost like a rapid deflation.

3. Repeat the process. When correctly done, your chest will expand when you breathe in and deflate when you breathe out. Continue doing this for five minutes.

4. With practice, speed up your breathing. Beginners should always start slowly to avoid hyperventilating, but over time, it will be possible to turn this into a rapid breathing technique. 
Method 2: Kapalbhati pranayam: Shining forehead breath

1. Inhale through your nostrils normally until your lungs are full. Keep your inhalation slow but unforced. First, feel the diaphragm move down, allowing the lungs to expand and forcing the abdomen out; then feel your chest expand with your collar bones rising last.

2. Exhale through both nostrils forcefully. This places the emphasis of the breath on the exhale rather than the (natural) inhale. Assist your exhalation by pulling in your stomach muscles to expel air. Exhaling should take much less time than it took to inhale.

- "Forced" exhalation means that the contraction of your stomach muscles helps push the air out of your body. It does not mean that the exhalation should be uncomfortable for you in any way

3. Repeat breaths for $\mathbf{1 5}$ minutes. You may take a minute rest after every five minutes.

Method 3: Anulom vilom pranayam: Alternate nostril breath

1. Close your eyes. Focus your attention on your breathing.

2. Close the right nostril with the right thumb. Simply press the thumb against your nostril to block it.

3. Inhale slowly through the left nostril. Fill your lungs with air. First, feel the diaphragm move down, allowing the lungs to expand and forcing the abdomen out; then feel your chest expand with your collar bones rising last.

4. Remove your thumb from your right nostril. Keep your right hand by your nose and your lungs full of air.

5. Use your ring and middle finger to close your left nostril. Most people find it easier to continue using the same hand to block either nostril, but you're welcome to switch hands depending on which nostril you're blocking. You can also switch if your arm gets tired

6. Exhale slowly and completely with the right nostril. Feel the collar bones dropping, chest deflating, and abdomen shrinking as the lungs collapse. When you've finished exhaling, keep your left nostril closed.

7. Inhale through the right nostril. Fill your lungs.
8. Close the right nostril and open the left.

9. Breathe out slowly through the left nostril. This process is one round of anulom vilom pranayam.

10. Continue for $\mathbf{1 5}$ minutes. You may take a minute's rest after every five minutes of exercise.

Method 4: Bahya pranayam: External breath

1. Inhale deeply through your nose. First, feel the diaphragm move down, allowing the lungs to expand and forcing the abdomen out; then feel your chest expand with your collar bones rising last.

2. Exhale forcefully. Use your stomach and diaphragm to push the air from your body. "Forced" exhalation means that the contraction of your stomach muscles helps push the air out of your body. It does not mean that the exhalation should be uncomfortable for you in any way.

3. Touch your chin to your chest and suck in your stomach completely. The goal is to leave a hollow below your ribcage, making it look like the front muscle wall of your abdomen is pressed against the back. Hold this position -- and your breath -- for as long as is comfortable.

4. Lift your chin and breathe in slowly. Allow your lungs to completely fill with air.

5. Repeat three to five times.

Method 5: Bhramari pranayam: Bee breath

1. Close your eyes. Focus on your breathing.

2. Place your thumbs in your ears, your index fingers above your eyebrows, and remaining fingers along the sides of your nose. Keep each pinky finger near a nostril.

3. Breath in deeply through the nose. First, feel the diaphragm move down, allowing the lungs to expand and forcing the abdomen out; then feel your chest expand with your collar bones rising last.

4. Use your pinkies to partially close each nostril. Keep your lungs filled.

5. Breathe out through the nose while humming. Note that the humming sound should originate in your throat, not as a result of your partially-blocked nostrils.

6. Repeat three times.

Method 6: Udgeeth pranayam: Chanting breath

1. Breathe in deeply through the nose. First, feel the diaphragm move down, allowing the lungs to expand 
and forcing the abdomen out; then feel your chest expand with your collar bones rising last

2. Exhale very slowly while saying $\mathbf{0 m}$. Allow the syllable to draw out as slowly as you can. Make sure to keep the 'O' long and the 'M' short. ("000000m.")

\section{Repeat three times.}

All the lung volume and capacities were estimated for the entire group of students after 15 days of breathing exercise session. The mean values of guided breathing exercises were compared with the mean values of the same parameters after breathing exercise using paired " $t$ " test. $P$ values of $<0.05$ was considered significant. Each subject acted as his own control.

Results were tabulated. Age, height and weight of each subject were recorded and body surface area was calculated.

\section{RESULTS}

Forty eight students were involved in the study. The mean age of subject was 21.05 years. The mean height was 1.61 meters. The mean weight of students was $57.3 \mathrm{~kg}$. The mean body surface area was 1.61 sq meter.

The values of the lung volume, capacities and percentage of FEV1/FVC parameters measured in subject before and after yoga breathing exercise depicted in Table 1.

Table 1: Parameters of lung volume, capacities, FEV1 and percentage of FEV1/FVC

\begin{tabular}{cllcccc}
\hline $\begin{array}{c}\text { S } \\
\text { No }\end{array}$ & Test & $\begin{array}{c}\text { Param- } \\
\text { eter }\end{array}$ & Mean & SD \pm SE & t value & p value \\
\hline 1 & Pre test & IRV & 1549.47 & $454.5 \pm 65.6$ & 4.97 & $0.0001^{*}$ \\
& Post test & & 1704.34 & $490.5 \pm 62.8$ & & \\
2 & Pre test & ERV & 1281.25 & $391.8 \pm 56.5$ & 3.5 & $0.004^{*}$ \\
& Post test & & 1450.62 & $461 \pm 73.8$ & & \\
3 & Pre test & TV & 505.72 & $145.4 \pm 20.9$ & -0.91 & 0.224 \\
& Post test & & 499.06 & $125.8 \pm 27.4$ & & \\
4 & Pre test & IC & 2056.25 & $507.5 \pm 73.2$ & 3.14 & $0.005^{*}$ \\
& Post test & & 2183.83 & $573.7 \pm 95.3$ & & \\
5 & Pre test & VC & 2973.95 & $683.2 \pm 98.6$ & 3.56 & $0.003^{*}$ \\
& Post test & & 3280.98 & $721.6 \pm 104.7$ & & \\
6 & Pre test & FVC & 3007.39 & $633.4 \pm 91.4$ & 2.99 & $0.006^{*}$ \\
& Post test & & 3219.91 & $718.3 \pm 105.6$ & & \\
7 & Pre test & FEV1 & 2398.60 & $710.7 \pm 102.5$ & 3.28 & $0.001^{*}$ \\
& Post test & & 2659.84 & $716.6 \pm 105.7$ & & \\
8 & Pre test & \%of & 80.21 & $14.7 \pm 2.1$ & 0.98 & 0.248 \\
& Post test & FEV1 / & 83.19 & $12.389 \pm 1.6$ & & \\
\hline & & FVC & & & & \\
\hline
\end{tabular}

*p value significance as it is $<0.05$

The mean value of tidal volume before exercise was 505.7 $\mathrm{ml}$ but after yoga breathing exercise it decreased up to $499 \mathrm{ml}$ which was statistically insignificant $(\mathrm{p}>0.05)$.

Mean inspiratory reserve volume of total subjects was $1549 \mathrm{ml}$ before exercise but after exercise it increased up to $1704 \mathrm{ml}$. Increment of inspiratory reserve volume was statistically significant $(\mathrm{p}<0.05)$.

The mean value of inspiratory capacity before exercise was $2056 \mathrm{ml}$ but after yoga breathing exercise it increased up to $2183 \mathrm{ml}$ which was statistically significant.

The mean expiratory reserve volume of total subjects was $1281 \mathrm{ml}$ before exercise but after exercise it increased upto $1450 \mathrm{ml}$. The increment was statistically significant $(\mathrm{p}<0.05)$.

The mean value of vital capacity before exercise was 2973 $\mathrm{ml}$ but after yoga breathing exercise it increased up to $3280 \mathrm{ml}$. The increments and p-value are significant.

The mean forced vital capacity of total subjects was 3007 $\mathrm{ml}$ before yoga breathing exercise but after yoga breathing exercise it increased up to $3219 \mathrm{ml}$.

The mean expiratory volume in one second was 2398 $\mathrm{ml}$ before exercise but after yoga breathing exercise it increased up to $2659 \mathrm{ml}$ which is highly significant.

The mean value of percentage of FEV1 was $80 \%$ before yoga breathing exercise it increased upto $82 \%$. The values are however statistically non-significant.

\section{DISCUSSION}

Yoga was practiced since more than one thousand years in Indian subcontinent. It consists of exercise of different body parts. Breathing exercises are one of them. Yoga is considered to be a very good exercise for maintaining proper health and also has a profound effect on the lung function of an individual. It is claimed that yogic practices help in prevention, control and rehabilitation of many respiratory diseases. Yoga breathing exercise increases compliance of lungs and thorax, airway resistance and strength of respiratory muscles ${ }^{16-20}$.

Some researchers like Vinayak P, Doijad et al ${ }^{16}$, Makwana $\mathrm{K}$ et $a l^{17}$, Joshi LN et $a l^{18}$, Yadav RK et $a l^{19}$ and Sodhi C et a ${ }^{20}$ had carried out study on effect of yoga breathing exercise on pulmonary or ventilatory functions and they all observed that following yoga breathing practice there was significant improvement in forced vital capacity (FVC) and timed vital capacity in one second (FEV1) but there was no significant change in tidal volume (TV) and percentage of timed vital capacity in one second (\%FEV1) ${ }^{16-20}$. This 
finding is similar to present study result.

\section{Tidal volume}

During quiet breathing, expiration is a passive process and is brought about by relaxation of the inspiratory muscles and lung recoil. Since contraction of the inspiratory muscles increases the size of the thoracic cage, relaxation of the same muscles decreases the size of the thoracic cage to the original. That is enough to generate positive pressure in the lungs to expel the normal tidal volume. Spirometric measurement of tidal volume varies from breath to breath.

Tidal volume was found to be less after yoga breathing exercises. The mean value of tidal volume before exercise was $505.7 \mathrm{ml}$ but after yoga breathing exercise it decreased up to $499 \mathrm{ml}$ which was statistically insignificant ( $p>0.05$ ).

\section{Inspiratory reserve volume and inspiratory capacity}

Inspiratory reserve volume and inspiratory capacity depend upon the use of accessory muscles of respiration. These forced breathing maneuvers depend on the strength of inspiratory muscles. These muscles have to be used to their maximum capacity to inhale the inspiratory reserve volumes.

Mean inspiratory reserve volume of total subjects was $1549 \mathrm{ml}$ before exercise but after exercise it increased up to $1704 \mathrm{ml}$. Increment of inspiratory reserve volume was statistically significant $(\mathrm{p}<0.05)$.

The mean value of inspiratory capacity before exercise was $2056 \mathrm{ml}$ but after yoga breathing exercise it increased up to $2183 \mathrm{ml}$ which was statistically significant. Better use of inspiratory muscles following yoga breathing exercise may be the reason for the increase in inspiratory reserve volume and inspiratory capacity.

\section{Expiratory reserve volume}

Expiratory muscles have to be used to their maximum capacity to expel the expiratory reserve volume. During forceful expiration abdominal muscles play an important role augmenting the expiratory pressure.

The mean expiratory reserve volume of total subject was $1281 \mathrm{ml}$ before exercise but after exercise it increased upto $1450 \mathrm{ml}$. The increment was statistically significant $(\mathrm{p}<0.05)$.

Better use of the expiratory muscles following yoga breathing exercise may be the reason for the increase in expiratory reserve volume. Decreased airway resistance may be indirectly contributing in the increase to expiratory reserve volume.

\section{Vital capacity}

Vital capacity depends on the strength of respiratory muscles compliance of lung and chest wall, airway resistance, integrity of pleura and thoracic structures. The mean value of vital capacity before exercise was $2973 \mathrm{ml}$ but after yoga breathing exercise it increased up to $3280 \mathrm{ml}$. The increments and p-value are significant. Yoga breathing exercises have resulted in increased values of vital capacity and forced vital capacity. This can be explained by better use of respiratory muscles, greater compliance and mobility of chest wall structures or decreased airway resistance following yoga breathing exercise.

\section{Forced vital capacity and forced expiratory volume in one second}

The mean forced vital capacity of total subjects was 3007 $\mathrm{ml}$ before yoga breathing exercise but after yoga breathing exercise it increased up to $3219 \mathrm{ml}$.

The mean expiratory volume in one second was 2398 $\mathrm{ml}$ before exercise but after yoga breathing exercise it increased up to $2659 \mathrm{ml}$ which is highly significant. FEV1 depends on the airway resistance. It is a test to differentiate obstructive lung disease and restrictive lung disease. Increased FEV1 may be due to lesser airway resistance after yoga breathing exercise.

\section{The percentage of FEV1}

The mean value of percentage of FEV1 was $80 \%$ before yoga breathing exercise, and it increased up to $83 \%$. The values are however statistically non-significant.

Some researchers claim effectiveness of yoga therapy, which may include improved pulmonary function, muscle relaxation, reduced anxiety levels. Yoga breathing exercises may be a better therapeutic modality since the present study revealed improved ventilatory function following yoga breathing exercises. This was evident from the increase in the value of inspiratory reserve volume, inspiratory capacity, vital capacity, expiratory reserve volume, forced vital capacity and forced expiratory volume in one second.

\section{CONCLUSION}

In conclusion, yoga breathing exercises are feasible and can improve lung function. It seems to be beneficial on respiratory efficiency. Further studies are required to establish the fact that whether yoga exercises can improve quality of life by preventing respiratory disorder. 


\section{REFERENCES}

1. Rodrigues MR, Carvalho CRF, Santaella DF, Filho GL, Marie SKN. Effects of yoga breathing exercises on pulmonary function in patients with Duchene muscular dystrophy: An exploratory analysis. J Bras Pneumol. March - April 2014; 40(2). Webpage:http:// dx.doi.org/10.1590/SI 806-37132014000200005.

2. Holland AE, Hill CJ, Jones AY, McDonald CF. Breathing exercises for chronic obstructive pulmonary disease. Cochrane Database Syst Rev. 2012; 10:CD008250.

3. Posadzki P, Ernst E. Yoga for asthma? A systematic review of randomized clinical trials. J Asthma. 2011; 48(6):632-9.

4. Field T. Exercise research on children and adolescents. Complement Ther Clin Pract. 2012; 18(1):54-9.

5. Giri PR., Sharma B, Jindal SK. Normal Spirometry in healthy natives of Bhutan. Journal of Association Physician, India.1996; 44:320-322.

6. Gansler EA. Analysis of ventilator defect by timed capacity measurement. Am Rev Tuberc. 1951; 64:256278.

7. Leslie A. Inspiratory expiratory vital capacity test of pulmonary function. American Journal of Medicine. 1952; 13: 809-812.

8. Knudson RJ, Slatin RC, Lebowitz MD. The maximal expiratory flow-volume curve: Normal standards, variability and effects of age. Am Rev Respir Dis. 1976; 113:587-600.

9. Polgar G, Wong TR. The functional development of respiratory system. American review of Respiratory Disease. 1979; 170:625-695.

10. Dickman DL, Schmidt Gardner RM. Spirometric standard for normal children and adolescents age 5 - 18 years. American Review of Respiratory Disease.
$1971 ; 104: 680-687$.

11. Culver $\mathrm{BH}$, Butler J. Alternation in pulmonary function: In principles of geriatric medicine. Anders R, Bierwman EL, Hazzard WR. 1985; 26:280-87.

12. Seely JE, Gujmen CA, Fecklake MR. Heart and lung function at rest and exercise in adolescents. Journal of applied physiology. 1974; 6:34-40.

13. Bye PTP, Farkas GA, Roussos C. Respiratory factors limiting exercise. Annual Review of physiology. 1983; 45:439-451.

14. Sobush DC. Breathing exercises: Laying a foundation for a clinical guideline. Cardiopulmonary Physical Therapy Journal. 1992; 3:8-10.

15. Bart Lett RH, Gazzaniga AB, Geraputy TR. Respiratory maneuvers to prevent post operative pulmonary complication: A critical review. JAMA. 1973; 224:1017.

16. Doijad VP, Surdi AD. Effect of short term yoga practice on pulmonary function tests. Indian Journal of Basic and Applied Medical Research. 2012; 1(3): 226-230.

17. Makwana K, Khirwadkar N, Gupta HC. Effect of Short term yoga practice on ventilatory function tests. Indian J Physiol Pharmacol. 1988; 32(3):202-8.

18. Joshi LN, Joshi VD, Gokhale LV. Effect of short term pranayam practice on breathing rate and ventilatory functions of lung. Indian J Physiol Pharmacol. 1992; 36(2):105-8.

19. Yadav RK, Das S. Effect of yogic practice on pulmonary functions in young females. Indian J Physiol Pharmacol. 2001; 45(4):493-6.

20. Sodhi C, Singh S, Dandona PK. A study of the effect of yoga training on pulmonary functions in patients with bronchial asthma. Indian J Physiol Pharmacol. 2009; 53(2):169-74. 